Editorial

\title{
Fence-Sitting and an Opportunity to Unsettle the Settled: Placing Critical Pressure on Creative Holography
}

\author{
Andrew Pepper \\ School of Art and Design, Nottingham Trent University, Nottingham NG1 4FQ, UK; andrew.pepper@ntu.ac.uk \\ Received: 21 February 2020; Accepted: 24 February 2020; Published: 5 March 2020 \\ check for \\ updates
}

\section{Introduction}

The field of creative holography is not known for its critical introspection. There is limited analysis of its development as a practice, process or methodology employed by artists. Artists struggle to place pressure on their own work in the medium. Their comments often slip into a diarised or practical declaration of the "how" rather than the "why".

A great deal of generalised reportage in popular media frames attempts to engage with clear commentary, critical observation and primary research. Critical analysis does exist but, as with many fringe or pioneering media, you really have to hunt for it. Critical pressure is not something a reader might casually come across in a contemporary art journal. Tenacity is required.

Frank Popper, in his review of art in the electronic age, commented that "[i]n order to build an historically legitimate aesthetic of holography one has to detach oneself from the dependence upon the photographic paradigm so important in understanding computer art. The persistence of this paradigm reveals itself especially in the overemphasised 'third' dimension of holography" (Popper 1993, p. 37). It is this "third" dimension on a flat surface, the illusion of "reality", which both attracts and distorts critical interrogation.

There appears to be a great deal of "fence-sitting" by artists, critics, curators, publishers and cultural observers. Commentators, including artists who work in the field, are unsure where creative holography "fits". It could be a remarkable and genuinely significant medium. However, it may not be, polluted as it is by the tacky commercialism of spectacular visual flotsam. A similar issue exists in other media. There is a world of terrible painting, sculpture, performance, installation, graphics, moving image and conceptual making. Why then is it so difficult to view a critical framework for holography? The worst of the worst in holography cannot be any less awful than the worst examples in other media.

\section{Tipping Point}

There appears to be a tipping point, which has not yet been reached, in the critical discussions around holography. The technical process is a little over 70 years old (Gabor 1948), and artists began to work with it as soon as it became viable as a display technique in the mid-1960s (Leith and Upatnieks 1965). Within three years, the first acknowledgement that this new technique might be relevant to artists appeared in the, then recently established, Leonardo journal (Wilhelmsson 1968). So, at most, it has been viable for artists for 55 years.

The use of video by artists is of a similar vintage. A recent survey and retrospective exhibition of work by Nam June Paik at Tate Modern in London attempted to chart the significant development of his practice in particular and video art in general-interwoven against a background of the Fluxus movement and enthusiasm for "new" technology. The exhibition drew on 50 years of cultural analysis, which has now generated further (current) critical observation around the impact the "father of video 
art" made on a changing media landscape (McMullan 2019). That type of "rolling" analysis has not happened, on a similar scale, with holography. This is not "sour grapes" on the part of myself and others working with holography (although it is easy and convenient to characterise it as such). It is fact.

The comparison between holography and video as media is clearly a blunt one. "Holes" can indeed be "picked" in it, but this type of basic overview can sometimes be helpfully provocative.

\section{Attempting to be Critical}

As we change decades, and 55 years on from a declared starting point, this Special Issue aims to offer a platform for critical discussion and a location for artists, curators, writers and cultural observers to place pressure on their practice or that of others invested in the field. The invitation to contribute cited the work of artist Margaret Benyon (1940-2016), her considerable and considered practice and the doctoral dissertation "How is Holography Art?", which she submitted to the Royal College of Art, London (Benyon 1994).

It is a fascinating read, all 226 pages of it, and it charts her attempt, through practice and precise critical analysis of the work she produced, to answer the question. It appears to be the most extensive catalogue and interrogation of a single artist's work by an artist who had developed a clear practice using holography. It has not been published, although attempts were made by Benyon to do so (Pepper 1995). Apparently, it was not thought to "have an audience", and that analysis is a persistent one. A literature review clearly indicates that the books that are published deal with the technical aspects of an optical process; generalised, procedural development; self-help or broad cultural observations framed from a scientific or engineering point of view. Within these publications, there are moments of critical commentary, but they lack depth, context or authority.

Through this Special Issue, there might be a more contemporary analysis 25 years after Benyon's attempted to untangle the question she posed.

This is a compact, nine-paper Special Issue. Makers and observers are still sitting uncomfortably on the fence. Authors who did submit their observations and opinions have contributed to what is, I hope, a significant "moment" in the reflective and critical analysis of the medium. It includes the following:

- Reflection by a range of artists on their extended and developing practice.

- The investigation of critical issues surrounding where holography "sits" in relation to other more traditional media.

- Analysis of the unique spatial qualities that holography offers and how aspects of the narrative are explored within a continuing practice.

- The impact of institutional collections within the broader "framing" of creative holography.

- The opportunity for holography to act as a progressive practice and research methodology within the traditional gallery.

- The curator's view, which examines the ephemeral document, a core point of reference within visual holography.

Not everyone felt able, or willing, to place pressure on their practice or dogmas, so I would like to thank those who are published here for their bravery and tenacity. I have witnessed the editorial process as these papers have developed during the past months and seen how robust editorial questioning has focused attention, exposed conflict and adjusted "voices". The cumulative result is a timely "litmus test", manifested through the observations of creative practitioners willing to investigate their practice (and possible insecurities) while attempting to place their activities in a more comprehensive, cultural and critical context. Perhaps, this Special Issue will become a moment of slight disruption. An opportunity to develop further questions that will place pressure on the critical values and aspirations of those who are developing holography as a medium, methodology and critical framework. 
Funding: This research received no external funding.

Conflicts of Interest: The author declares no conflict of interest.

\section{References}

Benyon, Margaret. 1994. How is Holography Art? Ph.D. thesis, Royal College of Art, London, UK.

Gabor, Dennis. 1948. A New Microscopic Principle. Nature 161: 777-78. [CrossRef] [PubMed]

Leith, Emmett, and Juris Upatnieks. 1965. Photography by Laser. Scientific American 212: 24-35. [CrossRef]

McMullan, Thomas. 2019. Nam June Paik At Tate Modern Review: How the 'Father of Video Art' Became a

Prophet. Available online: https://frieze.com/article/nam-june-paik-tate-modern-review-how-father-videoart-became-prophet (accessed on 15 February 2020).

Pepper, Andrew. 1995. Discussions with Margaret Benyon. Cologne: Academy of Media Arts Cologne.

Popper, Frank. 1993. Art of the Electronic Age. London: Thames and Hudson.

Wilhelmsson, Hans. 1968. Holography: A New Scientific Technique of Possible Use to Artists. Leonardo 1: 161-69. [CrossRef]

(C) 2020 by the author. Licensee MDPI, Basel, Switzerland. This article is an open access article distributed under the terms and conditions of the Creative Commons Attribution (CC BY) license (http://creativecommons.org/licenses/by/4.0/). 